\title{
ALGORITMA MODIFIED ARTIFICIAL BEE COLONY UNTUK MENYELESAIKAN MASALAH OPTIMASI MIXED-VARIABLE
}

\author{
Jamaliatul Badriyah \\ Universitas Negeri Malang \\ jamailatul.badriyah.mat@um.ac.id
}

\begin{abstract}
ABSTRAK
Pada penelitian ini, akan dibahas tentang modifikasi algoritma Artificial Bee Colony (algoritma $\mathrm{ABC}$ ). Pada dasarnya algoritma $\mathrm{ABC}$ ini merupakan algoritma yang dibangun untuk masalah optimasi dengan variabel kontinu. Sehingga untuk masalah optimasi yang melibatkan variabel bilangan bulat, diskrit, ataupun bulat 0-1 diselesaikan dengan cara membulatkan hasil ke bilangan terdekat. Terkadang, hasil dari pembulatan ini justru jauh dari optimal. Sehingga disini akan dikembangkan suatu algoritma yang merupakan modifikasi dari algoritma $\mathrm{ABC}$ yang mampu menangani masalah optimasi dengan variabel campuran yang selanjutnya akan diberi nama $\mathrm{M}$ ABC. Kemudian algoritma M-ABC ini akan diuji cobakan pada masalah teknik yang sudah terkenal seperti Pressure Vessel Design, Speed Reducer Design Optimization, dan Tension/Compression Spring Design. Hasil dari penerapan kami mengindikasikan bahwa algoritma $\mathrm{M}-\mathrm{ABC}$ ini merupakan algoritma yang menjanjikan untuk menyelesaikan masalah optimasi dengan variabel campuran.
\end{abstract}

Kata kunci:Artificial Bee Colony, Optimasi Mixed-Variable

\begin{abstract}
This research focuses on modifying Artificial Bee Colony Algorithm (ABC Algorithm). Basically, ABC algorithm can handle optimization problem which only involve Continue variables. Moreover, the optimization problems which involve other variables, such as discrete and zero-one variables, are solved by rounding the result to the nearest value. Sometimes, that result is far from optimum value. Therefore, it will be modified the $\mathrm{ABC}$ algorithm which can solve the mixed variables optimization problems. This algorithm will be called as M-ABC Algorithm. This algorithm is validated using three standardized engineering design problems, which are Pressure Vessel Design, Speed Reducer Design, and Tension/Compression Spring Design. The results indicate that $\mathrm{M}-\mathrm{ABC}$ Algorithm is a promising algorithm to solve mixed variable optimization problem.
\end{abstract}

Keywords: Artificial Bee Colony, Mixed-Variable Optimization 


\section{Pendahuluan}

Akhir-akhir ini, banyak berkembang metode optimasi metaheuristik yang terinspirasi dari alam (Nature-Inspired), seperti Genetic Algorithms (GA), Differential Evolution (DE), Particle Swarm Optimization (PSO), Artificial Bee Colony (ABC), Ant Colony Optimization (ACO), Firefly Algorithm (FA), Cuckoo Search (CS) dan masih banyak lagi. Algoritma optimasi metaheuristik ini dirasa bisa memberikan solusi yang hampir mendekati solusi. Sehingga algoritma optimasi tersebut bisa lebih fleksibel untuk menyelesaikan masalah optimasi nonlinear. Pada dasarnya, algoritma optimasi metaheuristik dikembangkan untuk menangani masalah optimasi yang hanya melibatkan variabel kontinu. Masalah optimasi yang melibatkan variable bulat atau diskrit, diasumsikan sebagai masalah optimasi dengan variabel kontinu, kemudian bilangan bulat atau diskrit yang terdekat dipilih sebagai solusi. Pemilihan solusi seperti ini, terkadang memberikan hasil yang jauh dari nilai optimum [8].

Pada kenyataannya, banyak masalah optimasi yang melibatkan variabel diskrit, atau bulan seperti pada masalah optimasi desain teknik. Seperti pada masalah Pressure Vessel Design, Algoritma ... (Jamaliatul Badriyah) dimana ketebalan silinder utama dan ketebalan ujungnya merupakan variabel diskrit yaitu kelipatan bulat dari 0,0625 inci, sedangkan jari-jari dan panjang silinder utamanya merupakan variabel kontinu. Begitu pula pada masalah Speed Reducer Design Optimization, dimana seluruh variabelnya adalah variabel kontinu kecuali banyaknya gigi dalam pinion $\left(\mathrm{x}_{3}\right)$. Oleh karena itu, diperlukan algoritma optimasi yang secara khusus dapat mengatasi masalah Mixed-Variable dengan solusi yang mendekati solusi sebenarnya. Beberapa penelitian telah melakukan modifikasi terhadap algoritma metaheuristik, seperti pada algoritma DE [5, 8], FA [2], PSO [3], dan ACO [4, 9], sedemikian sehingga algoritma optimasi tersebut dapat mengatasi masalah optimasi Mixed-Variable.

Algoritma ABC merupakan salah satu metode optimasi metaheuristik yang terinspirasi dari tingkah laku lebah madu. Pada algoritma ini, terdapat 3 kelompok lebah yaitu lebah pekerja (Employed Bees), Onlooker Bees, dan Scouts Bees. Employed Bees bertugas membawa informasi mengenai sumber makanan yang dia datangi. Scouts Bees bertugas mencari sumber makanan baru disekitar sarang. dan Onlooker Bees bertugas menunggu di sarang dan menemukan sumber makanan baru 
melalui informasi yang diterima dari Employed Bees. Setiap Employed Bees hanya mendatangi satu sumber makanan. Banyaknya Employed Bees atau Onlooker Bees menyatakan banyaknya solusi dalam populasi. Algoritma ABC telah diterapkan ke berbagai masalah optimasi dan terbukti memberikan hasil yang baik $[6,7]$. Pada penelitian ini, akan dilakukan modifikasi terhadap algoritma ABC sehingga algoritma tersebut dapat mengatasi masalah optimasi MixedVariable. Modifikasi ABC (M-ABC) diterapkan pada tiga masalah desain teknik, yaitu Pressure Vessel Design, Speed Reducer Design Optimization, dan Tension/Compression Spring Design. Kemudian hasil dari M-ABC akan dibandingkan dengan beberapa hasil dari penggunaan algoritma optimasi lain, yaitu Simple Constrained Particle Swarm Optimizer (SiC-PSO) [3], Real Code Steady State GA ( AP Mrc ) [9], dan PPA [11].

\section{Optimasi Mixed-Variable}

Suatu masalah optimasi MixedVariable merupakan masalah optimasi yang melibatkan berbagai macam variabel meliputi variabel bulat, real (kontinu), diskrit, dan/atau biner, serta fungsi obyektif dan/atau kendala yang taklinier. Variabel biner atau yang biasa disebut zero-one variables adalah variabel yang bernilai 0 atau 1 . Sedangkan variabel diskrit merupakan kelipatan dari suatu bilangan tertentu. Pada umumnya, masalah optimasi Mixed-Variable dapat dirumuskan seperti berikut $[1,8]$ :

$$
\text { Minimumkan }
$$

$\mathrm{f}(\mathrm{W}, \mathrm{X}, \mathrm{Y}, \mathrm{Z})$

Dengan kendala:

$$
\begin{aligned}
& \mathrm{g}_{\mathrm{i}}(\mathrm{W}, \mathrm{X}, \mathrm{Y}, \mathrm{Z}) \leq 0 \\
& \mathrm{~h}_{\mathrm{j}}(\mathrm{W}, \mathrm{X}, \mathrm{Y}, \mathrm{Z})=0
\end{aligned}
$$

\section{Dimana}

$\mathrm{i}=1, \ldots, \mathrm{m} ; \mathrm{j}=1, \ldots, \mathrm{l}$

$\mathrm{W}=\left(\mathrm{w}_{1}, \mathrm{w}_{2}, \ldots, \mathrm{w}_{\mathrm{nz}}\right) ; \mathrm{W} \subseteq\{0,1\}$

$\mathrm{X}=\left(\mathrm{x}_{1}, \mathrm{x}_{2}, \ldots, \mathrm{x}_{\mathrm{nc}}\right) ; \mathrm{X} \subseteq \mathbb{R}$

$\mathrm{Y}=\left(\mathrm{y}_{1}, \mathrm{y}_{2}, \ldots, \mathrm{y}_{\mathrm{ni}}\right) ; \mathrm{Y} \subseteq \mathbb{Z}$

$\mathrm{Z}=\left(\mathrm{z}_{1}, \mathrm{z}_{2}, \ldots, \mathrm{z}_{\mathrm{nd}}\right) ; \mathrm{z}_{\mathrm{i}}=\mathrm{p} . \mathrm{q}$

$\mathrm{p} \in \mathbb{R}, \mathrm{q} \in \mathbb{N}$

$$
\begin{aligned}
& \mathrm{x}_{\mathrm{a}}{ }^{(\mathrm{L})} \leq \mathrm{x}_{\mathrm{a}} \leq \mathrm{x}_{\mathrm{a}}{ }^{(\mathrm{U})} ; \mathrm{a}=1, \ldots, \mathrm{nz} \\
& \mathrm{y}_{\mathrm{b}}{ }^{(\mathrm{L})} \leq \mathrm{y}_{\mathrm{b}} \leq \mathrm{y}_{\mathrm{b}}{ }^{(\mathrm{U})} ; \mathrm{b}=1, \ldots, \mathrm{ni} \\
& \mathrm{z}_{\mathrm{c}}{ }^{(\mathrm{L})} \leq \mathrm{z}_{\mathrm{c}} \leq \mathrm{z}_{\mathrm{c}}{ }^{(\mathrm{U})} ; \mathrm{c}=1, \ldots, \mathrm{nc}
\end{aligned}
$$

$\mathrm{f}(\mathrm{W}, \mathrm{X}, \mathrm{Y}, \mathrm{Z})$ merupakan fungsi obyektif dan (W, X, Y,Z) merupakan solusi. Variabel $\mathrm{W}, \mathrm{X}, \mathrm{Y}, \mathrm{Z}$ secara berturut-turut menyatakan variabel biner, bilangan real, bilangan bulat, dan diskrit dengan banyaknya variabel $\mathrm{n}_{\mathrm{z}}+\mathrm{n}_{\mathrm{c}}+$ $\mathrm{n}_{\mathrm{i}}+\mathrm{n}_{\mathrm{d}}=\mathrm{n}$

\section{Algoritma Artificial Bee Colony}

Tereshko mengembangkan suatu model tentang perilaku kelompok lebah 
madu dalam mencari makanan berdasarkan persamaan reaksi difusi [6, 7]. Model ini menjelaskan tentang perilaku lebah madu dalam memilih sumber makanan (nektar) dan meninggalkan sumber makanan yang sudah tidak bisa dimanfaatkan lagi.

Berdasarkan model yang dikembangkan oleh Tereshko tersebut, Karaboga [6] mengembangkan suatu algoritma optimasi yang disebut dengan Artificial Bee Colony Algorithm yang selanjutnya akan disebut dengan algoritma ABC. Pada algoritma ini, terdapat 3 kelompok lebah yaitu lebah pekerja (Employed Bees), Onlooker Bees, dan Scouts Bees. Employed Bees bertugas mendatangi sumber makanan dan menentukan banyaknya nektar didalam sumber makanan tersebut kemudian membagi informasinya kepada Onlooker Bees yang menunggu di sarang. Kemudian Onlooker Bees membuat keputusan tentang sumber makanan mana yang akan dipilih dimana sumber makanan dalam algoritma ini menyatakan solusi yang mungkin dari masalah optimasi dan banyaknya nektar menyatakan kualitas (fitness) solusi. Setiap Employed Bees hanya mendatangi satu sumber makanan sehingga banyaknya Employed Bees sama dengan banyaknya sumber Algoritma ... (Jamaliatul Badriyah) makanan. Employed Bees yang sumber makanannya sudah dihabiskan kemudian menjadi Scout Bees. Banyaknya Employed Bees atau Onlooker Bees menyatakan banyaknya solusi dalam populasi.

\section{Eksperimen dan Diskusi}

Pada penelitian kali ini akan dibentuk suatu algoritma yang merupakan modifikasi dari algoritma ABC yang selanjutnya akan disebut sebagai algoritma Modified Artificial Bee Colony (M-ABC). Algoritma M-ABC ini dirancang untuk mengatasi keterbatasan dari algoritma ABC. Algoritma M-ABC ini dirancang agar mampu menyelesaikan masalah optimasi Mixed-Variable.Secara garis besar, tahapan dalam algoritma M$\mathrm{ABC}$ ini hampir sama dengan tahapan dalam algoritma ABC. Tahapan dalam algoritma $\mathrm{M}-\mathrm{ABC}$ ini dapat dibedakan menjadi 5 tahap dengan penjelasan sebagai berikut.

- Inisialisasi

Pada tahapan ini, populasi awal akan dibangkitkan dengan aturan seperti berikut.

AdMathEdu | Vol.7 No.2 | Desember 2017 


$$
\begin{gathered}
\mathrm{W}_{\mathrm{i}, \mathrm{j}}=\operatorname{randi}(2)-1 \\
\mathrm{X}_{\mathrm{i}, \mathrm{j}}=\mathrm{BB}_{\mathrm{j}}+\operatorname{rand}[0,1]\left(\mathrm{BA}_{\mathrm{j}}\right. \\
\left.-\mathrm{BB}_{\mathrm{j}}\right)
\end{gathered}
$$$$
Y_{i, j}=\operatorname{randi}\left(\min _{j}, \max _{j}\right)
$$$$
\mathrm{Z}_{\mathrm{i}, \mathrm{j}}=\operatorname{randi}\left(\min _{\mathrm{j}}, \max _{\mathrm{j}}\right) * \mathrm{p}
$$

$$
\text { Setelah populasi }
$$

awal

dibangkitkan kemudian dicari fitness untuk masing-masing sumber makanan dengan aturan:

$$
\mathrm{fit}_{\mathrm{i}}=\left\{\begin{array}{l}
\frac{1}{1+\mathrm{f}_{\mathrm{i}}}, \mathrm{f}_{\mathrm{i}} \leq 0 \\
1+\left|\mathrm{f}_{\mathrm{i}}\right|, \mathrm{f}_{\mathrm{i}}>0
\end{array}\right.
$$

\section{- Employed Bee}

Pada tahap ini, Employed Bee mencari sumber makanan baru dengan menggunakan persamaan

$$
\begin{gathered}
b_{i, j}=a_{i, j}+\operatorname{rand}[0,1]\left(a_{i, j}-a_{k, j}\right) \\
v_{i, j}=\left\{\begin{array}{cc}
b_{i, j}, & a_{i, j} \notin \mathbb{Z} \\
\operatorname{round}\left(b_{i, j}\right), & a_{i, j} \in \mathbb{Z}
\end{array}\right.
\end{gathered}
$$

- Onlooker Bee

\section{- Scout Bee}

Ketika ada Scout Bee dalam suatu siklus, maka harus ada sumber makanan baru yang ditemukan dengan menggunakan aturan

$$
\begin{gathered}
\mathrm{W}_{\mathrm{i}, \mathrm{j}}=\operatorname{randi}(2)-1 \\
\mathrm{X}_{\mathrm{i}, \mathrm{j}}=\mathrm{BB}_{\mathrm{j}}+\operatorname{rand}[0,1]\left(\mathrm{BA}_{\mathrm{j}}\right. \\
\left.-\mathrm{BB}_{\mathrm{j}}\right) \\
\mathrm{Y}_{\mathrm{i}, \mathrm{j}}=\operatorname{randi}\left(\min _{\mathrm{j}}, \max _{\mathrm{j}}\right) \\
\mathrm{Z}_{\mathrm{i}, \mathrm{j}}=\operatorname{randi}\left(\min _{\mathrm{j}}, \max _{\mathrm{j}}\right) * \mathrm{p}
\end{gathered}
$$

- Mekanisme penanganan kendala

Untuk masalah optimasi dengan kendala, maka mekanisme penanganan kendala menjadi sangat penting salah satunya adalah dengan fungsi penalti. Fungsi penalti ini mentransformasikan masalah dengan beberapa kendala menjadi suatu masalah tunggal tak berkendala atau menjadi barisan masalah tak berkendala [13]. Misalkan suatu masalah optimasi didefinisikan seperti berikut.

$$
\text { Minimumkan } f(X)
$$

Dengan kendala

$$
\begin{aligned}
& g(X)=0 \\
& h(X) \leq 0
\end{aligned}
$$

$$
\mathrm{i}(\mathrm{X}) \geq 0
$$

Maka masalah tersebut dapat diransformasikan menjadi: 
Minimumkan

$$
\begin{aligned}
& \mathrm{f}(\mathrm{X})+\mu_{1} \mathrm{~g}^{2}(\mathrm{X}) \\
& +\mu_{2} \operatorname{maximum}\{0, \mathrm{~g}(\mathrm{X})\} \\
& +\mu_{3} \operatorname{minimum}\{0, \mathrm{i}(\mathrm{X})\} \\
& \multicolumn{1}{c}{\text { Dengan kendala }}
\end{aligned}
$$

$\mathrm{X} \in \mathbb{R}^{\mathrm{n}}$

$$
\text { dan } \mu_{\mathrm{i}} \text { merupakan suatu }
$$

parameter penalti.

Secara umum, pseudo code untuk algoritma M-ABC dapat dituliskan sebagai berikut.

INPUT DATA SN, D, Max, limit, $\left[\mathrm{BB}_{\mathrm{j}}: \mathrm{BA}_{\mathrm{j}}\right], \mathrm{j}=1,2, \ldots, \mathrm{D}$

1: Generate initial food source

2: Evaluate its fitness and its objective value

$$
\begin{aligned}
& \text { 3: Cycle } 1 \\
& \text { 4: Repeat } \\
& \text { 5: For each Employed Bees } \\
& \text { \{ }
\end{aligned}
$$

find new solution, evaluate its fitness, evaluate its objective value, apply greedy selection \}

6: Calculate $\mathrm{p}_{\mathrm{i}}$ for each solution using ()

\section{7: For each Onlooker Bees \{}

Select solution depend on $\mathrm{p}_{\mathrm{i}}$, find new solution, Algoritma ... (Jamaliatul Badriyah) evaluate new solution, apply greedy selection

\}

8: If there are solutions abandoned

Then replace with new solution using ()

9: remember the best solution

10: cycle $=$ cycle +1

11:Until cycle $=$ Max

Algoritma M-ABC ini kemudian diimplementasikan pada beberapa masalah teknik yang memuat variabel campuran. Adapun masalah teknik yang digunakan adalah Pressure Vessel, Speed Reducer, dan Tension/Compression Spring. Kemudian hasil yang didapatkan dibandingkan dengan hasil dari beberapa penerapan algoritma yang lain untuk masalah yang sama yang didapat dari beberapa referensi yang ditemukan yaitu Sic-PSO [3], APM ${ }^{\mathrm{rc}}$ [9], dan PPA [11].

Hasil dari penerapan algoritma M-ABC dapat dilihat pada lampiran 2 . Dari hasil tersebut terlihat bahwa algoritma $\mathrm{M}-\mathrm{ABC}$ memberikan hasil yang lebih baik pada setiap uji. Selain itu, dilihat dari mean dan standar deviasinya, M-ABC memberikan hasil yang relatif stabil. Oleh karena itu, algoritma M-ABC ini merupakan algoritma yang bagus untuk menyelesaikan masalah optimasi 
dengan variabel campuran berdasarkan robust, dan kestabilannya. Untuk penelitian selanjutnya, kami akan mencoba menggunakan algoritma M$\mathrm{ABC}$ ini untuk diterapkan ke masalahmasalah yang lain yang memuat variabel campuran seperti pada optimasi portofolio.

\section{Pustaka}

Bazaraa, Mokhtar S, dkk. 2006. Nonlinear Programming: Theory and Algorithms, 3rd Edition. John Wiley \& Son, New York.

Brajevic, I. dan Iignjatovic J. An Enhanced Firefly Algorithm For Mixed Variable Structural Optimization Problems. Ser. Math. Inform. Vol. 30, No 4 (2015), 401417.

Cagnina, Leticia C. dan Esquivel Susana C. 2008. Solving Engineering Optimization Problems with the Simple Constrained Particle Swarm Optimizer. Informatica 32 (2008) 319-326 319.

Dorigo, Marco. Ant Colony Optimization for Continous and Mixed-Variable Domains. Krzysztof Socha of IRIDIA, CoDE, Universit'e Libre de Bruxelles, CP 194/6, Av. Franklin D. Roosevelt 50, 1050 Brussels, Belgium.

Gao Yuelin, Zaimin Ren, dan Yang Gao. 2011. Modified Differential Evolution Algorithm of Constrained Nonlinear Mixed Integer Programming Problems. Information Technology Journal 10 (11): 2068-2075. ISSN 1812-5638/ DOI:10.3923/itj.2011.2068.2075.
Karaboga, Dervis dan Bahriye Akay. 2009. A Comparative Study of Artificial Bee Colony Algorithm. Applied Mathematics and Computation 214 (2009) 108-132.

Karaboga, Dervis and Celal Ozturk. 2011. A Novel Clustering Approach: Artificial Bee Colony (ABC) Algorithm. Applied Soft Computing 11 (2011) 652-657.

Lampinen J., Zelinka I. Mixed IntegerDiscrete-Continuous Optimization by Differential Evolu- tion Part 1:

The Optimization Method In: Osmera Pavel (ed.) (1999). Proceedings of MENDEL'99,

International Mendel COnference on Soft Computing, June 9.-12. 1999, Brno, Czech Republic Brno University of Technology, Faculty of Mechanical Engineering, Institut of Automation and Computer Science, Brno (Czech Republic), pp. 71-76. ISBN 80-214-1131-7.

Liao, Tianjun. 2011. Improved Ant Colony Optimization Algorithms for Continous and Mixed-DiscreteContinous Optimization Problem. Université Libre de Bruxelles, Faculté des Sciences Appliquées, CODE - Computers and Decision Engineering, IRIDIA - Institut de Recherches Interdisciplinaires et de Développements en Intelligence Artificielle.

Liao, Tianjun dkk. 2013. An Unified Ant Colony Optimization Algorithm for Continuous Optimization. IRIDIATechnical Report Series ISSN 1781-3794.

Sulaiman, Muhammad dan Salhi, Abdellah. 2015. A Seed-Based Plant Propagation Algorithm: The Feeding Station Model. The 
Scientific World Journal, Vol.

2015. 